\title{
A Wasted Opportunity During a Pandemic: The Foreign Medical Graduates in the USA
}

\author{
Kamalika Roy ${ }^{1}$ (I) $\cdot$ Natalia Solenkova ${ }^{2} \cdot$ Parth Mehta $^{3}$ \\ Accepted: 5 July 2021 / Published online: 28 July 2021 \\ (c) The Author(s), under exclusive licence to Springer Science+Business Media, LLC, part of Springer Nature 2021
}

\begin{abstract}
In this brief note from the field, we address an essential issue of non-inclusion of Foreign Medical Graduates (FMG) practicing in the US into the healthcare disaster response in the current pandemic. Because FMGs represent a significant share of the entire country's physician workforce, it seems not prudent to ignore the need to address the current immigration barriers affecting the crucial healthcare needs during this pandemic. Being subjects of the ongoing complex bureaucracy complicated by recent anti-immigrant steps, FMGs that practice for years on temporary (H1B) visas cannot fully join COVID-19 forces. In addition, these physicians face multiple challenges related to their health protection, protection of their immediate family, job security, and the potential risk of being deported. We believe that physicians' immigration status should no longer be disregarded outside of academic interest. It carries the same importance as other public health issues, especially in severe healthcare crises like this pandemic.
\end{abstract}

Keywords Pandemic $\cdot$ Immigrant physicians $\cdot$ USA $\cdot$ H1-B visa $\cdot$ Primary care $\cdot$ Physician shortage $\cdot$ Underserved Healthcare legislation

\section{Introduction}

During the COVID-19 pandemic, the US healthcare system has seen some unique challenges, exposing many of its pre-pandemic deficits in structure, scope, and access. As epidemiologists suggest a protracted pandemic, with grim statistics in many states, it is imperative to optimize the healthcare disaster preparedness and mobilization of healthcare resources, including all available healthcare resources. In an effort to enhance the physician workforce, many states simplified their licensing and regulatory requirements, called for retired physicians, and graduated medical students early. However, the States could not mobilize a specific group of qualified physicians. This group consists of thousands of Foreign Medical Graduates (FMGs) who completed their

Kamalika Roy

royk@ohsu.edu

Oregon Health and Science University, Portland, OR, USA

2 Critical Care Medicine, Memorial Healthcare System, Hollywood, FL, USA

3 Department of Internal Medicine, University of Illinois, Peoria, IL, USA training in the US, obtained one or more board certifications, and practiced with independent medical licenses. These physicians usually practice in underserved areas on a temporary work visa (H1B) while awaiting permanent residency. Federal immigration restrictions prohibit them from serving beyond a specific geographical address, leading to the restriction of their deployment in some worst affected areas during the pandemic. FMGs account for 33\% of independently practicing primary care physicians and one-fourth of the physician workforce in this country [1]. Some specialties like geriatric medicine, nephrology, internal medicine, cardiology, endocrinology, critical care medicine, psychiatry, etc. have 30-50\% FMGs in their workforce [1]. However, several complexities are involved in the interface between healthcare and immigration, and unless resolved, they prohibit the utilization of FMGs as a part of crisis response in the pandemic.

\section{FMGs' Legal Immigration and Pathway to Practice}

FMGs are physicians who completed their medical schools outside of the US. They go through the same requirements to enter residency training in the US to obtain a license to 
practice medicine. The requirements include multistep board examinations, like the US medical school graduates, and an additional certification by the Educational Council for Foreign Medical Graduates (ECFMG), and a visa sponsorship. The vast majority of FMGs obtain residency training under an exchange visitor visa sponsored by the ECFMG for residency and fellowship training [2]. However, after the training, physicians can only practice independently on an H1B visa. As $\mathrm{J} 1$ is an exchange visitor program, it requires the beneficiary to return to their home country after their training for at least two years. However, given the decades-long shortage of physicians in the Health Professional Shortage Area (HPSA), in 1994, North Dakota senator Kent Conrad introduced a program, popularly known as Conrad 30, waiving the two-year home country return requirement, in exchange for serving in the HPSA areas for at least three years [3]. Other Interested Government Agencies (IGA) grant such waivers to recruit these board-eligible or boardcertified physicians in the HPSA and rural areas. Most J1 physician trainees avail these programs, as training and practice requirements in the US are very different than those in their home country, even if they had to return. While the waiver programs only waive the need to return, these physicians still need an H1B visa sponsored by the prospective employers to initiate practice in these underserved areas. H1B visas are often issued for three years but, more recently, for a lesser duration. This visa needs to be renewed every few years, for a maximum of six years, and it can be renewed beyond the six-year period when the sponsoring employer files an employment-based permanent residency application. Even with an approved permanent residency application, a physician might have to wait in the line (and renew their H1B visa every few years) for years to decades, depending upon their country of origin. This note from the field focuses on these FMGs who completed training and are on an H1B visa, either within the first six years or stuck in a backlog for permanent residency for years.

\section{The Unequal Comparison Between Two Industries}

Over the past several years, almost exclusive use of H1B visas by technology giants made this visa essentially synonymous with the technology industry. On the contrary, physician shortage remained a complicated matter in each Association of American Medical Colleges (AAMC) report since the early $90 \mathrm{~s}$. In the most recent report, there is a projected shortage of 139,00 physicians by 2033 with a shortage of $>55,000$ primary care physicians, despite the inflow of Advanced Practice Registered Nurses (APRN) providers [4]. Among all FMGs, $41 \%$ practice in primary care disciplines [5]. Though the scope of employment in the healthcare industry is not comparable with that of the technology industry, these visa restrictions still apply to physicians. Unlike technology job applicants, these physicians are vetted by the same standard of competitive meritbased national selection criteria that every American medical graduate goes through to get into a residency. In this pandemic, the increasing gap between healthcare demands and doctors' supply became more prominent, disproportionately so in specific settings like inpatient hospitals, intensive care, and emergency rooms. A wave of disease burden from chronic diseases and mental health disorders is expected to be a 'tsunami' in the coming months, where more community-based services will be sought. A similar trend was noticed after the Spanish Flu in 1918, where inpatient psychiatric hospitalization went up by 7.2 factors in the following six years [6]. Researchers found that the influenza death rates in the US were significantly related to a higher rate of suicide following the 1918 pandemic, independent of alcohol and the World War II-related events [7]. Non- COVID-19 cancer patients are found to face delays in care during the pandemic in the context of a reduction in practice [8]. None of these trends are considered in the decision-making about legal immigration for physicians.

\section{Restrictions for Physicians on a Work Visa}

The physicians on an H1B visa are limited by the worksite restriction (can serve only in one geographical address, mentioned in their H1B petition) and the bureaucratic process of 'prevailing wage determination' for 'labor condition application' by the Department of Labor. These two processes involve several month-long multi-step advertisements, wait period and paperwork, before an employer can initiate an H1B petition for a physician. The whole process is not only used to initiate a new H1B application but repeated with each renewal every few years. This several-step cumbersome process ensures that no potential employment opportunity is replacing American physicians with an immigrant physician. Still, it undermines the current mismatch between the demands and supply of doctors during this pandemic. Due to the worksite restriction, these physicians cannot even practice telemedicine or help out at an additional COVID-19 affected area though they are willing. Some physicians have described it as 'a fireman sitting out a house fire', as stated by Senator Dick Durbin (IL-D) in his Congressional Testimony [9]. Though the pandemic has no geographical boundaries, and these physicians are often the only specialists available in the critical access hospitals, the worksite restriction remains a barrier to deploy their skills in the areas of need. 


\section{Unequal Distribution of Physicians Across the Country}

The discrepancy is even more prominent when the disparities across the socio-geographic areas are considered. Despite an influx of Advanced Practice Registered Nurses (APRN), the disparity in the primary care providers' distribution remained striking between the federally designated underserved areas and urban and suburban areas. Physicians on a visa commonly practice in underserved areas with a higher poverty rate. They are $42.5 \%$ of physicians where per capita income is less than $\$ 15,000$ a year [10]. In severely COVID-19 affected states like New York, Florida, Texas, Arizona, Illinois, and Michigan, these physicians are double the national average representation [11]. The work site restriction and lengthy labor condition application, and prevailing wage determination remain barriers to effective dissemination of FMG workforce. The work site barriers restrict an H1B physician from serving in a second clinic or do telemedicine a building apart or help out an emergency room on a different street, a mile away, within the same underserved area. During the pandemic that flexibility is needed, as the demand overwhelmed the supply. However, immigration laws are not aligned with any such nuanced information.

\section{Administrative Proclamations are Unduly Affecting Physicians}

As the pandemic progressed into its protracted undulating course claiming lives of $>500,000$ Americans [12], all physicians, irrespective of their immigration status and nationality devoted themselves in caring for Americans with their inadequate protective gears, without any breaks in their schedule and at the risk of contracting the deadly disease. While non-citizen physicians have the same responsibility, burden, and uncertainty at work, they also are responsible for ensuring their legal status by either renewing their work visa or changing their status (from employment to training). In an unprecedented effort to disrupt legal immigration, the previous administration issued several proclamations, including a recent one [13], without explicit exemption for these physicians serving the communities during the pandemic. As a result, a few hundred new physicians (on both $\mathrm{J} 1$ and H1B visas) were delayed in their home countries, waiting to start their residency training in American hospitals dependent on them for ongoing patient care. While many of those consulate officers recognized these physicians' visa applications were 'vital' for America's healthcare system, many did not. The proclamation directed the Department of Homeland Security to address the scope of exemptions of visa ban for 'certain physicians'; however, there was no clear guideline to the consulates despite strong advocacy efforts from national and state medical organizations and professional societies [14]. Overall, there is an increasing trend in the H1B denial rate in the last five years, according to the National Foundation of American Policy report [15].

\section{Decades-Long Wait Time to Receive a Stable Status}

By all means, FMGs are the backbones of healthcare delivery in many settings. However, their approved permanent residency might take decades to up to 151 years, depending on their country of birth [16]. Indian origin physicians constitute more than half of all international medical graduates, and they are the worst affected in the wait time category. The most significant impact of the backlog is psychological. To live under constant fear of deportation if something goes wrong, despite doing everything right, can be demoralizing and traumatic. Under US immigration law, their immigration status is tied to their employment. In case of death or disability, there will be an end of legal status for them, leading to deportation for these physicians and their families, including their US-born minor children, despite having an approved application for permanent residency. To make the matter worse, these physicians may not be eligible to receive disability benefits despite paying insurance premiums. The physicians' disability insurance companies do not allow benefits to the physicians who would have to move back to their home country. When disabled, these physicians would lose their H1B status. Their ability to work is the only means to maintain their H1B status and stay legally in this country without a permanent residency status.

\section{Bottom Line: A Stalemate and Potential Solutions}

In summary, the restrictive steps by the administration and the already outrageous backlog in permanent residency for legal immigrants take a hefty toll on immigrant physicians and their families, who have been serving in this country for years, waiting for their approved permanent residency applications. During this pandemic, these warriors are on the frontlines taking care of COVID-19 patients while facing the risks of potential death and disabilities, like all other physicians. However, in case of their death and disabilities, their family and aging out children face the risk of deportation, unlike other physicians, who are not on a visa. During their decade-long wait, these physicians also fight to overcome the 
Fig. 1 Proposed advocacy matrix for potential short- and long-term solutions for physicians' immigration backlog

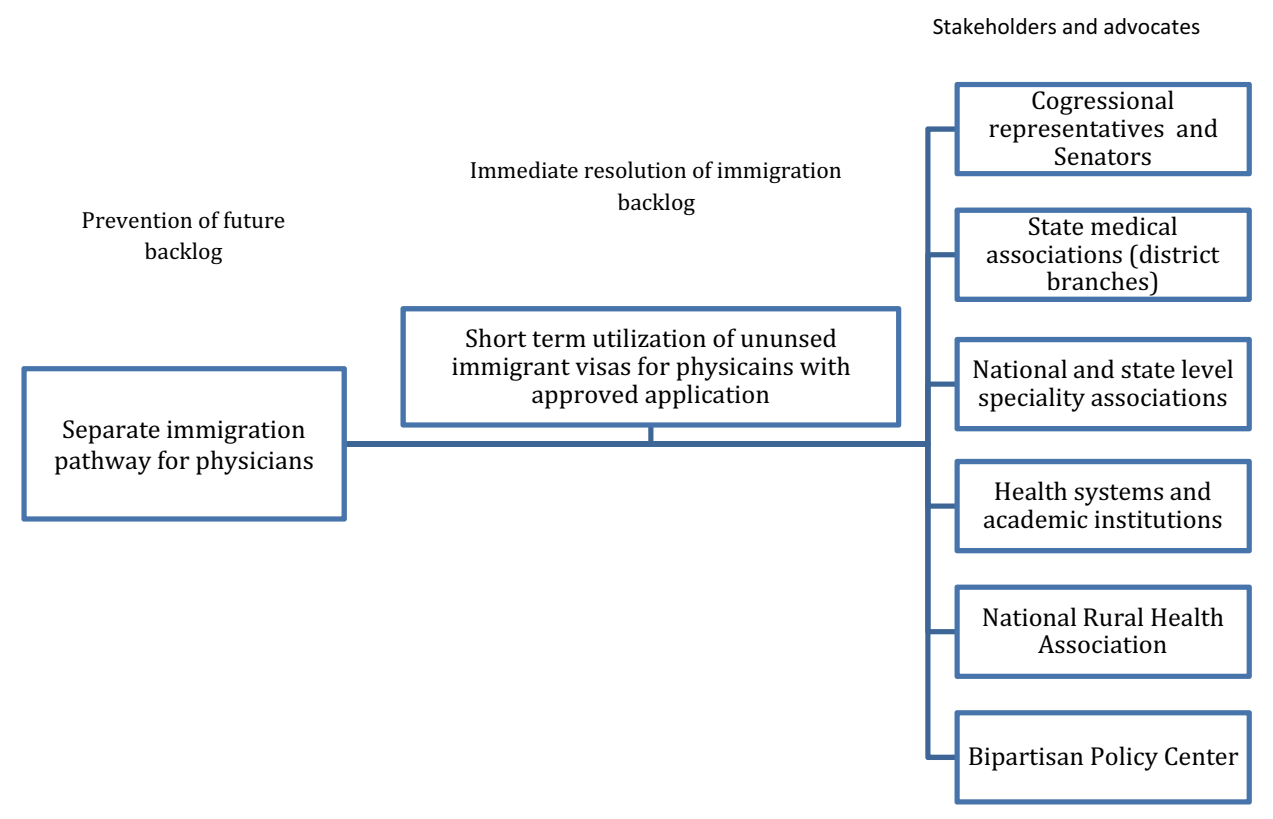

ever-increasing hurdles of an unfriendly immigration system and its poorly laid out interface with the healthcare needs in this country.

Immigration is a complex and thorny subject. In today's partisan environment, where there is an extreme ideological divide, any bigger immigration reform is unlikely to happen for the foreseeable future. After all, there is no single immigration reform bill that has come out of Congress since the efforts made in 2005 [17]. In the last 15 years, there has been absolute stalemate on this topic, and the future looks bleak to this group of physicians. These physicians find themselves in an unsustainable backlog have lost their faith in the system as they don't see any light at the end of the tunnel. While these are federal matters, they affect the states in the context of the care they provide. National professional associations should collaborate with the state medical societies to create FMG sections/taskforces and inform the congressional representatives and the senators to facilitate specific legislation. Other stakeholders like the affected health systems, academic institutions, the National Rural Health Association, and the Bipartisan Policy Center should actively advocate facilitating the much-needed legislation, as outlined in Fig. 1.

A short-term solution is to recapture the unused or wasted Immigrant visa (green cards) over the last few decades. This solution does not increase the total number of green cards. It does not increase the net immigration level, as it does not propose hiring more physicians from outside of the country. Between the American Competitiveness in the 21st Century Act in 2000 [18] and the 2005 emergency supplemental appropriations bill [19], Congress has recaptured nearly 200,000 unused immigrant visas. Those recaptured by the
2005 bill were exclusively for nurses. There are bills in the Senate and the Congress [20] that propose recapturing immigrant visas that remained unused or were wasted over the last fifteen years, exclusively for doctors and nurses, with a specific attestation that these doctors would not replace American workers (Fig. 1). The other long-term solution would be to pass the legislation that creates a separate pathway of permanent status for the physicians serving in the HPSA areas after a stipulated duration of service [21]. Common sense piecemeal reforms like these are possible when lawmakers across party lines put their differences aside and rally their support for the healthcare needs during this protracted pandemic.

Funding They also declare no funding supporting this manuscript.

\section{Declarations}

Conflict of interest All three authors declare no potential conflicts of interests in this manuscript.

\section{References}

1. Active Physicians Who Are International Medical Graduates (IMGs) by Specialty. 2017. Aamc.org. https://www.aamc.org/ data-reports/workforce/interactive-data/active-physicianswho-are-international-medical-graduates-imgs-specialty- 2017. Accessed 18 Jan 2021.

2. ECFMG 2020 Information Booklet. ECFMG. https://www.ecfmg. org/2020ib/j1-visa-sponsorship.html. Published August 27, 2019. Accessed 18 Mar 2021. 
3. Conrad 30 Waiver Program. USCIS. https://www.uscis.gov/worki ng-in-the-united-states/students-and-exchange-visitors/conrad-30waiver-program. Published May 15, 2020. Accessed 18 Mar 2021.

4. The Complexities of Physician Supply and Demand: Projections From 2018 to 2033. Aamc.org. Published June 2020. https://www. aamc.org/system/files/2020-06/stratcomm-aamc-physician-workf orce-projections-june-2020.pdf. Accessed 18 Jan 2021.

5. 2013 State Physician Workforce Data Book Center for Workforce Studies. 2013. In: State Physician Workforce Data Report. Association of American Medical Colleges. https://www.aamc.org/datareports/workforce/report/state-physician-workforce-data-report

6. Mamelund, Svenn-Erik. 2003. Effects of the Spanish Influenza Pandemic of 1918-19 on Later Life Mortality of Norwegian Cohorts Born About 1900.

7. Wasserman IM. The impact of epidemic, war, prohibition and media on suicide: United States, 1910-1920. Suicide Life Threat Behav. 1992;22(2):240-54.

8. Patt D, Gordan L, Diaz M, Okon T, Grady L, Harmison M, Markward N, Sullivan M, Peng J, Zhou A. Impact of COVID-19 on cancer care: how the pandemic is delaying cancer diagnosis and treatment for american seniors. JCO Clin Cancer Informat. 2020;4:1059-71. https://doi.org/10.1200/CCI.20.00134.

9. Congress.gov. https://www.congress.gov/116/crec/2020/05/12/ modified/CREC-2020-05-12-pt1-PgS2383-2.htm. Published 2020. Accessed 18 Mar 2021.

10. Foreign-trained doctors are critical to serving many U.S. communities. Americanimmigrationcouncil.org. Published January 17, 2018. https://www.americanimmigrationcouncil.org/resea $\mathrm{rch} /$ foreign-trained-doctors-are-critical-serving-many-us-commu nities. Accessed 18 Jan 2021.

11. American Medical Association. Doctors will beat COVID-19. Let's bring more of them to the fight. Ama-assn.org. https://www. ama-assn.org/about/leadership/doctors-will-beat-covid-19-lets-bring-more-them-fight. Accessed 18 Jan 2021.

12. CDC. COVID-19 cases, deaths, and trends in the US. cdc.gov. Published March 28, 2020. https://covid.cdc.gov/covid-data-track er/. Accessed 18 Jan 2021

13. Travel.state.gov. 2020. Proclamation Suspending Entry of Immigrants and Nonimmigrants Who Present Risk to the U.S. Labor Market During the Economic Recovery Following the COVID-19
Outbreak. [online] Available at: https://travel.state.gov/content/ travel/en/News/visas-news/proclamation-suspending-entry-ofimmigrants-and-nonimmigrants-who-present-risk-to-the-USlabor-market-during-the-economic-recovery-following-theCOVID-19-outbreak.html. Accessed 16 Mar 2021.

14. Robeznieks A. 2020. Why IMG physicians are vital to U.S. health security. [online] American Medical Association. Available at: https://www.ama-assn.org/education/international-medical-educa tion/why-img-physicians-are-vital-us-health-security. Accessed 16 Mar 2021.

15. NFAP.com. 2020. H-1B and L-1 Visas I National Foundation of American Policy. [online] Available at: https://nfap.com/issues/ h-1b-and-1-1-visas/. Accessed 16 Mar 2021.

16. Bier DJ. 150-year wait for Indian immigrants with advanced degrees. Cato.org. Published June 8, 2018. https://www.cato. $\mathrm{org} / \mathrm{blog} / 150$-year-wait-indian-immigrants-advanced-degrees. Accessed 18 Jan 2021.

17. Weiner R. How immigration reform failed, over and over. The Washington Post. https://www.washingtonpost.com/news/the-fix/ wp/2013/01/30/how-immigration-reform-failed-over-and-over/. Published April 28, 2019. Accessed 18 Mar 2021.

18. Title I-American competitiveness in the Twenty-First Century. 2000, October.

19. Emergency Supplemental Appropriations Act for Defense, the Global War on Terror, and Tsunami Relief. 2005;151;2005.

20. Perdue D. S.3599 - 116th Congress (2019-2020): Healthcare Workforce Resilience Act. Congress.gov. https://www.congress. gov/bill/116th-congress/senate-bill/3599. Published May 5, 2020. Accessed 18 Mar 2021.

21. Klobuchar A. S.948 - 116th Congress (2019-2020): Conrad State 30 and Physician Access Reauthorization Act. Congress. gov. https://www.congress.gov/bill/116th-congress/senate-bill/ 948. Published March 28, 2019. Accessed 18 Mar 2021.

Publisher's Note Springer Nature remains neutral with regard to jurisdictional claims in published maps and institutional affiliations. 